\title{
The power of peers in GTA development of practice: evaluation of an equal-status teaching observation project
}

Kerry Dobbins ${ }^{1}$, Neil F. Adams ${ }^{2}$, Ellen Bishop ${ }^{2}$, Mehman Ismayilli ${ }^{3}$, Martha Papadopoulou ${ }^{2}$, Megan L. Phillips ${ }^{4}$, Nadine Tauchner ${ }^{5}$, Elizabeth van Wessem ${ }^{5}$ and Joe Watkins ${ }^{6}$

${ }^{1}$ Leicester Learning Institute, University of Leicester, UK

${ }^{2}$ School of Geography, Geology and the Environment, University of Leicester, UK

${ }^{3}$ School of Business, University of Leicester, UK

${ }^{4}$ Leicester Law School, University of Leicester, UK

${ }^{5}$ School of History, Politics and International Relations, University of Leicester, UK

${ }^{6}$ Department of Genetics and Genome Biology, University of Leicester, UK

\begin{abstract}
Peer observation of teaching is a well-established professional development practice and can occur through a range of different activities (e.g., micro-teaching, lesson study, performance reviews, etc.). There is evidence that these various activities are being increasingly used to support Graduate Teaching Assistants (GTAs). This paper reports the findings of a pilot project that implemented equal-status, interdisciplinary and developmental peer observations. As a collaborative project, it was co-designed and evaluated by eight GTAs and an academic developer. Our observation framework involved GTAs' undertaking the observee and observer roles and retaining five of six identified dimensions of control. The findings show that the observation experiences encouraged both new and experienced GTAs to take a self-reflective and critical stance to their teaching and disciplinary approaches. This confirms the value of GTAs' experiencing the observer role and their exposure to other disciplinary environments. The post-observation 'learning conversations' provided significant opportunities for GTAs to discuss and reflect on their practice contexts and experiences together. This represents an effective example of peer supported learning, which also reduces the sense of isolation that GTAs often experience.
\end{abstract}

Keywords: Graduate teaching assistants, peer observation, $\mathrm{PhD}$ students, professional development, teaching practice

\section{Introduction}

This paper presents an evaluation of a pilot project for the peer observation of teaching designed by and for graduate teaching assistants, or GTAs, at the University of Leicester. By 'GTAs', we refer specifically to PhD students who undertake a considerable amount of teaching activity (following Stocks, 2018). Substantial research and scholarly attention have already been directed towards the impact of this professional development activity on teachers' practice (e.g., Gosling, 2002; Hammersley-Fletcher and Orsmond, 2005; Hendry, Bell, and Thomson, 2014; 
Torres et al., 2017). This paper offers a unique perspective to this literature in that it represents the final outcome of a project that has been a fully collaborative endeavour between eight GTAs (Neil, Ellen, Mehman, Martha, Megan, Nadine, Liz and Joe) and an academic developer (Kerry). There is recognition of the value of observation experiences for GTA development and recent years have seen a growing focus on them as an area for research and investigation. For example, Reinholz, Cox and Croke (2015) and Reinholz (2017) report findings from projects involving Mathematics GTAs in a peer observation or peer review process. Sozer, Zeybekoglu and Alayli (2019) discuss the benefits emerging for GTAs from observed micro-teaching activities. Further investigations explore the use of disciplinary peer mentors (Lockwood, Miller and Cromie, 2014; Joyce and Hassenfeldt, 2020), lesson study activities (Deshler, 2015; Lampley, Gardner and Barlow, 2018) and co-teaching experiences (Howlett and Nguyen, 2020). Our study adds another layer to this research by exploring an interdisciplinary peer observation process that engaged GTAs as co-designers, evaluators and disseminators of the project. In this way, they have also been introduced to and directly involved in the scholarship of teaching and learning (SoTL) by embracing and enacting its key features.

\section{Theoretical framework}

The benefits of peer observation for teacher professional development (i.e., those within a permanent and/or full-time academic role) are well established, particularly when undertaking the role of the observer (Chamberlain, D'Artrey, and Rowe, 2011; Drew et al., 2017; Hendry et al., 2014; Torres et al., 2017). This role has been recognised as helping teachers to become more self-reflective through the "double-seeing" (Tenenberg, 2016, p. 765) process of considering one's own practice through the comparison to other classrooms and learning environments observed. Without the weight of leading the session on the observers' shoulders, they can focus attention on student learning and behaviours that they may not usually have scope to register and reflect on when in the teaching role. Reinholz (2017, p. 2) particularly equates the observer role to one that can bring significant opportunities for "enhanced noticing" of student thinking.

As indicated previously, there is emerging evidence of peer observation practices (in a variety of formal and informal ways) being used to support GTA development. GTAs often occupy an uncertain space within higher education (HE). They are usually relatively new to teaching; however, they may not necessarily be recognised as 'teaching staff' by their institution. Various studies report GTAs' experiences of being caught in a space somewhere between student and lecturer; students view them as teachers but lecturers view them, at most, as teaching assistants (Raaper, 2018). The liminality of their role can raise questions about how best to support them and the types of support that they can access (Beaton, 2017). Indeed, the nature, timing and institutional location (i.e., centrally based or department-specific) of training programmes have been discussed for many years and continue to be debated within the literature (Chadha, 2013; Lueddeke, 1997; Stocks, 2018). The liminality of the GTA role also has implications for the positioning of observation schemes where they are deployed as part of formal training opportunities. Conduct of teaching observations by a senior or experienced academic may frame the experience as more evaluative than developmental. Additionally, it is 
unlikely that the experience will be reciprocal (i.e., the GTA observing the academic and providing feedback) and so opportunities for GTAs to develop self-reflective practices and enhance their noticing of student thinking may be more limited in this type of process.

By contrast, a growing body of evidence suggests that when GTAs have been involved in peer (specifically equal-status) observation or peer review of teaching projects, there are significant benefits to the development of their self-critique and reflective thinking skills (Reinholz, Cox and Croke, 2015; Howlett and Nguyen, 2020). Reinholz's (2017) study of Mathematics GTAs also found that observing and giving feedback to each other encouraged them to feel less isolated in their roles and part of a professional learning community sharing similar worries, concerns and challenges.

It was the benefits reported by these scholars - as well as the considerable evidence cementing the value of the observer role for enhancing professional practice - that led to the inception of the project that is the focus of this paper. Whilst the pilot project was initially the idea of the academic developer, a fundamental feature of it was that it would be a fully collaborative endeavour by the GTA group, from the planning and design stages through to evaluation and dissemination. A co-owned project would ensure that the ethos of peer support and development remained the central tenet. Additionally, as a pilot project, it was important to have GTAs' involvement from the beginning so that they themselves would design the observation process specifically to meet their own self-identified needs, as opposed to what the academic developer might have assumed those needs to be.

A further benefit of this collaboration is that it explicitly engages the GTAs in the scholarship of teaching and learning. Peer observation undoubtedly involves individuals in a scholarly activity (i.e., through observations they are gaining evidence to reflect on their own teaching practices). However, in this project, the GTAs are also evaluating their (individual and peer) reflections and disseminating to the wider educational community the learning gained. These are the key features of a SoTL-aligned peer observation framework, as presented by Engin (2016). Consequently, our paper adds to the growing GTA-focused literature by presenting a richer picture of the GTAs' experiences through their co-evaluation of the impact of the project on their practices.

\section{Peer observation project design}

McMahon, Barrett, and O'Neill (2007) argue that the established categorisations of peer observation models - e.g., Gosling's (2002) evaluative, developmental and peer review categories - are problematic owing to the disparity of power or lack of trust that may exist between observer and observed, particularly in the two former categories. For example, it is questionable whether an observation that is being carried out for summative reasons by a superior (as in the evaluative model) or an academic developer (as in the developmental model) can really be described as a peer observation. Instead, McMahon et al. (2007) propose two types of peer observation (or third-party observation, as they refer to it) based on who has more control within the experience. In their Type-A categorisation, control is maintained by the 
observee who retains exclusive access to the information generated by the observation and decides what, if anything, is reported and how. In contrast, control is maintained by others within the Type-B categorisation, who can report on and distribute the observation outcomes without the consent of or consultation with the person observed. According to McMahon, Barrett, and O'Neill (2007), only the Type-A category can be legitimately called peer observation.

Our project falls soundly within this Type-A categorisation, with the GTAs retaining five of the six identified dimensions of control. Specifically, they had:

- control over whether or not to participate;

- control over the focus of the observation;

- control over how feedback was given (including control over the structure of the form and documentation used);

- control over all information generated by the observation;

- control over what is done as a result of the observation.

The only dimension that they could not control was the choice of observer; the pilot nature of the project did not allow this. An outline of how the project was implemented will demonstrate how these elements of control were enacted.

The project ran over the 2018-19 academic year. In September 2018, prior to the commencement of teaching, the academic developer put a call out to GTAs across the University, which resulted in eight volunteer participants. At two meetings, convened in September and October, we collaboratively decided on the observation groups, protocols and documentation. Being experienced in this area, the academic developer provided information to help inform discussions (e.g., presenting a range of observation documents from various institutions for the group to review), but all decisions about the observation process were made collectively. The GTAs involved were from a range of disciplines (including members of five schools and departments across the University's College of Life Sciences, College of Science and Engineering, and College of Social Sciences, Arts and Humanities). This interdisciplinarity was embraced by the group so that individuals could observe student learning in contexts and environments that might be quite different to their own. To ensure that the project was achievable within their already heavy workload of teaching and $\mathrm{PhD}$ research activities, we agreed that individuals would be observed twice (by different observers) and would undertake the observer role twice. This schedule meant that the process was not a one-off experience and would provide the GTAs with opportunities to reflect after each experience and put their learning into practice for a further observation or discussion. To make logistics easier to manage, the group was split into two sub-groups of four; each group intentionally contained a mix of disciplines and teaching experience. Again, for practical ease, the academic developer created the observation schedules (i.e., who would be observing whom, which was the only element of control not maintained by the GTAs). It was, however, their responsibility to review their teaching timetables and organise observation dates with their respective observers.

The process agreed by the group was that each observation experience would consist of a preobservation discussion, the observation itself and a post-observation de-brief. Whilst this is a 
fairly established peer observation process (Race, 2009), the GTAs themselves decided the points included in the form used to guide the discussions. It was particularly important that observees could direct their observers to such aspects of their practice as would provide them with the specific feedback they wanted. The documentation was designed in such a way as to ensure that each observation was a learning experience for both parties (see appendix 1). For example, the observer was also directed to consider what aspects of practice or student learning they might like to focus on in the environment that they would be observing. The postobservation de-brief was called a 'learning conversation' to emphasise the importance of both parties' reflecting on and discussing the observation experience, rather than its simply being a one-way feedback process to the observee. Additionally, the form used during the observation was designed to be open and flexible rather than directive. After reviewing various examples, the GTAs were opposed to a tick-box approach (e.g., does the teacher identify the session learning outcomes? Yes/No) and ones that listed many areas for the observer to comment on (e.g., introduction to the session, pace of the session, teacher's tone of voice, etc.). They considered such observation documents to be unwieldy, artificial and potentially constrictive. Instead, they chose just two key headings to direct the observer's notes. These headings were 'student engagement observations' and 'teaching approach/activities observations'. The observations took place between October 2018 and May 2019. The academic developer routinely kept in touch with the GTAs throughout the period to retain contact and be available to help resolve any difficulties - such as in arranging observations - though none, in fact, arose.

\section{Evaluation design}

A qualitative approach was taken to the evaluation of the project. After all observation experiences were completed, a meeting - held with each group of four GTAs (conflicting timetables prevented us from meeting as a whole group at this point) - enabled discussion of the GTAs' experiences of the following: being the observee; being the observer; giving feedback to each other; the interdisciplinary aspect of the project; and impact on their teaching practices. These key points related to the particular priorities of this project. The academic developer led the discussions to ensure that the key points were addressed but at the same time allowed the conversations to accommodate what the GTAs wanted to discuss. With the dimensions of control as an analytical frame, the academic developer identified which transcribed extracts from the discussions related to each dimension. For each dimension, and to manage and present the data efficiently, the developer combined and interwove relevant discussion threads from both groups, taking care to avoid possible misrepresentation of comments. Each GTA then analysed one extract (roughly a page in length) and provided a summary of the key themes emerging within it. This process ensured respondent validation of the interwoven extracts, but more importantly, enabled the GTAs to be involved in analysis of the data in a manageable and achievable way. The summaries are presented in the following findings section. All the voices of the people involved in this project are therefore heard below and the GTAs themselves have been key to interpreting and drawing out the important learning points. 


\section{Findings}

The findings section explores the GTAs' experiences and perspectives of the observation project through the framework of the dimensions of control. As explained above, extracts from the evaluation discussions are presented and the GTAs have analysed and summarised them to identify the key themes emerging.

\section{Control over whether to participate}

In the evaluation meetings, the GTAs discussed their various reasons for wanting to be involved in the project. To provide an example of how the collaborative process of evaluating the project worked in practice, the full interwoven extract relating to this dimension of control is presented below, followed by Neil and Megan's summary of the key themes emerging:

Neil: I had been observed once or twice at another institution but the idea of doing it as a group sounded very interesting. I was also interested in developing my teaching practice.

Joe: I thought learning more about the process of developing teaching would be interesting, which is something we're not usually exposed to. Also, I thought I was a quite good demonstrator and teacher but I knew that I could improve and it was difficult to work out how so it gave me an opportunity to delve into that more easily.

Nadine: Similarly for me, I had an inkling about things I was not doing right and I wanted someone to see that and tell me, to make it really clear to me. And I was curious to see other people teaching and how they approach things.

Liz: That was a big thing for me, the chance to see other people's teaching and learn about some other disciplines.

Neil: When we were defining the groups that was one of the things that I was quite keen to have, diversity of teaching styles, group sizes, that kind of thing. I thought that would be really useful.

Megan: I'm interested in questions like 'what specifically is my role in this type of teaching?' and doing a comparison with other roles in other disciplines can help you to understand your own role more.

Martha: I was curious about what other people are doing in other areas and I was also curious about how you do observing actually.

Ellen: I saw this as a chance to just begin reflecting on my own teaching. I'm in the first year so this is really my first proper experience of teaching. It was to start myself off being self-reflective from the beginning in the hopes that it would feed into teaching in the future. 
Summary (Neil and Megan)

The motivations for participating in the project varied between individuals and extended beyond simply wanting to improve our own individual teaching practices. Firstly, motivations were shown to vary with the level of prior teaching experience. Those with less teaching experience viewed the project as an opportunity to begin the process of self-reflection. They hoped that by starting this practice early in their careers, improvements could be fed into their future teaching. Those with more teaching experience saw the project as an opportunity to develop our existing practices. It was hoped that having the perspective of other GTAs would help in the constructive identification of possible changes in practice that could benefit both us as teachers and our students' learning. The opportunity to take part in group observations with peers and to learn more about how the observation process works were also motivations for some to participate.

Another key set of motivations behind participation involved the interdisciplinary nature of the project and its multiple teaching contexts. Specifically, we were curious about how GTAs taught in other disciplines. To experience the teaching of others and their approaches was seen as a valuable opportunity. Similarly, the inclusion of multiple teaching session styles (e.g., demonstrating, seminars, and tutorials) and multiple group sizes (e.g., entire undergraduate year groups, seminar groups, and small tutorial groups) was attractive. This was because it allowed the possibility of direct comparison with teaching similar to our own, but also the possibility to learn from different teaching contexts. The prospect of this comparison with other types of teaching was also viewed as a potential way to prompt reflection on our own role when teaching. The opportunity to be involved in observations between different disciplines (across the arts and sciences) was also important in motivating participation, because it allowed exposure to types of teaching that some of us might not experience in our own discipline.

\section{Control over the focus of the observation}

Martha summarises the benefits raised by the GTAs of being able to control the focus of their observations. The pre-observation discussion was the point of the process at which the GTA being observed was able to identify particular aspects that $s /$ he wanted the observer to focus on.

\section{Summary (Martha)}

Being able to control the focus of the observation was one of the key elements in the project and one of great importance. As individuals from different disciplines, with different experience levels in teaching and often with different instructions from module coordinators, a universal observation form would have been difficult to apply to all of us. For example, non-native English speakers (like myself) may want part of the observation focused on their wording selection and how/if they are making themselves understandable enough for their students. Other GTAs were equally interested in what the students thought of their teaching and by asking observers to focus on that, they gained some useful information. On the other hand, there was also the opportunity to mention to the observer what not to focus on. This was useful because some of us were constrained by directions from module coordinators about how to support students in 
sessions and others had physical limitations that prevented them from moving around the room or standing at the whiteboard:

Megan: It was also useful to say what not to observe me on. Because of my physical limitations, I can't stand at the board for most of the session and write things down so I've had to be innovative. So I could explain that I can't physically do this so there's no point recommending it.

Reflecting on the project, the creation of a more individual and flexible observation that the observer and observee co-created through the pre-observation discussion had multiple benefits for us as participants. Firstly, it gave us the chance to direct the observation, thus creating a truly collaboratively environment. Importantly, it also ensured that we tangibly benefited from the post-observation discussions as we gained constructive and valuable comments on the points that we specifically wanted to get feedback on.

\section{Control over observation process (including structure and documentation) and method of feedback}

As part of the collaborative process, all involved agreed that the project should embrace an interdisciplinary element. Additionally, all wanted the observation documentation to be loosely structured and flexible enough that each observation experience, including the post-observation discussion, could suit the specific needs of those involved and not constrain any flow of learning opportunities. In the evaluation meetings, discussions focused on the value of these points and how they led to and supported a powerful process of self-reflection.

\section{i. The value of interdisciplinary observations}

Joe and Liz summarise the benefits experienced by the GTAs from observing peers in different disciplines.

\section{Summary (Joe and Liz)}

The observations were particularly useful because it was deliberately cross-disciplinary, rather than within our own disciplines. This gave us all a chance to ignore the content of the teaching and focus on delivery instead. In fact, the more we failed to understand what could be very technical teaching the more it actually helped. This is because it meant we could see the techniques being used and have time to consider how to adapt it to our own teaching, whether that be in the present or future, classroom-based or fieldwork, university-based or elsewhere. Being away from our own subject specialities allowed us to focus not on the subject matter but on how other people dealt with situations in teaching common to many of us, such as encouraging participation from quieter students.

The ability to draw similarities from differences was a common theme. For example, Martha likened techniques observed from unfamiliar small group tutorial settings in Law and History to fieldwork study in Geology: 
I found it very useful because even though small group tutorials are completely different to what l'm used to in Geology and as a PhD demonstrator, there are also field trips where you have to lead a small group and to see a completely different way of teaching, like how you handle a small group, how you bring things up, how you start the discussion, how you keep the discussion alive, was very useful.

Feedback on teaching during fieldwork is often very difficult to organise due to logistical issues. However, by observing across disciplines Martha was able to get useful teaching tips that she would have struggled to obtain from observing large lectures or demonstrations.

Some of us not only reflected on our own personal teaching experiences, but also those of our respective departments. Practices can become ingrained within disciplines or departments and this project was seen to help identify complacency and potentially challenge dogmatic practices:

Neil: Departments may have specific ways of teaching things that have become ingrained over many years and they might not be the best ways... they might need someone to question 'could we do this instead?'. And that might have come from observing someone in a different department or using different techniques.

At least one GTA wanted to take methods observed in other disciplines and approach their department about utilising those techniques.

\section{ii. The value of the 'learning conversations' (post-observation discussions)} Nadine identifies the key reasons that the post-observation discussion was such a powerful experience for the GTAs.

\section{Summary (Nadine)}

An essential element to the success of the pilot project was the post-observation discussion. In addition to providing the feedback that was collected during the observation, these discussions offered the opportunity and space for an exchange of experience and took the form of learning conversations. In contrast to more conventional teaching observations, where a superior gives feedback about your performance, the post-observation meeting with a peer was less intimidating and therefore led to fruitful discussions about teaching styles and issues. This exchange had the added effect of making participants realise that they are not alone with their struggles and worries. Another output of those conversations was the sharing of solutions and methods to tackle some of the issues teachers may experience. Overall, the post-observation discussion proved to be a valuable experience for both the observer and observee because it offered time to immediately reflect upon what they had seen and experienced during the observation and to exchange their teaching experiences in general.

\section{iii. A powerful process for self-reflection}

In the evaluation meetings, all the GTAs confirmed that the three-stage observation process collaboratively agreed upon did encourage and support a significant amount of self-reflection. Ellen summarises the various ways in which the project led to this valuable activity. 


\section{Summary (Ellen)}

The nature of this project encouraged a great deal of self-reflection. Before the session that was being observed, a pre-discussion took place between the observer and observee in which they discussed contextual details of the class (e.g., class size, year group and GTA role) and challenges that might be encountered. This discussion was really helpful for the person being observed to reflect before the session on potential challenges they may face and how to maximise good teaching practices during the session:

Neil: I found that the pre-observation discussion forces you to reflect before you even begin the session...so I found in the sessions that I was being observed compared to just my normal teaching, I actually probably taught better just because I had taken that time to reflect before the session on what I might need to do to maximise the students' experience in the room. I realised that I should spend a bit of time before a session thinking through the challenges I might expect in particular sessions.

Surprisingly, many of us taking part in the project found that being the observer, rather than the observee, was the most insightful element of the project. Whilst being observed and getting direct feedback on specific aspects of teaching practice was really helpful, it was difficult to reflect on your own teaching whilst focusing on academic content and how to help students. However, observing someone else teach gave the opportunity to reflect on our own teaching based on how someone else teaches. That it was an interdisciplinary project meant that observations were focused on teaching style rather than content. This was particularly helpful when undertaking the observer role because it provided an opportunity to reflect deeply on our own teaching practices and how other people approach teaching activities in a different way. The feedback form we created had a specific section to prompt and record self-reflections whilst observing someone else, considering what can be learnt from the delivery of teaching we were observing and the impact of our own teaching style on how students engage in the class. Observing other people's teaching gave many of us new ideas about teaching techniques and ways we can engage students, which we have since incorporated into our own practices:

Liz: I found that when I was being observed, I didn't have time to think about what I was doing, I was just in teacher mode with the students...But when you're doing the observing you're not thinking about the content, you're thinking about delivery and how that impacts on your own teaching so you're making your own notes, not only to give feedback to your observee but notes to say, that's a really good technique, I should do that. It's a double process if you like.

\section{Control over what is done as a result of the observation}

All the GTAs retained control over the form that they completed as part of the observation experience. Some chose to share them with their observation group and with the academic developer while others did not. As indicated above, many talked in the evaluation meetings of changes that they had made to their practices based on feedback received or methods they had observed. Importantly, though, it was entirely their choice as to how or if they took any action. In 


\section{Articles}

the summary below, Mehman describes the steps he chose to take and the lasting impact of the observation experiences.

\section{Summary (Mehman)}

The outcome of this project is invaluable to me because it was the first time that I received feedback regarding my teaching. The feedback was constructive and insightful, describing all the key points that I needed to develop. After each of the observations, I tried to act on the feedback as much as possible. Every time I taught in the last semester, I constantly asked myself: "If the observers were watching my teaching again, would they recognise that I followed their advice?" All the observations I experienced taught me that sometimes the tiny details I had neglected could be an important part to complete the puzzle.

\section{Discussion}

Our findings confirm that peer observation can be incredibly valuable, both for new and experienced GTAs. Our findings also reinforce the value of observations that are truly peerfocused (i.e., equal status participants) and where the GTAs retain control over many of the elements of the process, particularly the aspects on which they would like to get feedback. Without a disparity in power or concern about performance being judged by a more experienced other or against potentially constraining criteria, the GTAs in this project were less intimidated (as Nadine suggests) and experienced many of the benefits identified in studies of this area. In particular, there was a sense of reassurance and feeling less alone, as reported by Reinholz (2017) and Hendry et al. (2014). Supporting findings by Torres et al. (2017), the observations and following learning conversations encouraged the sharing of practices and motivated the GTAs to reflect on their individual methods and, in some cases, their disciplinary approaches too. What appears particularly valuable to them was the learning that they gained through taking on the observer role. Liz echoes Tenenberg's (2016) “double-seeing" argument when she refers to the "double process" of considering your own practices through the act of observing the practices of others. Consequently, our findings show that much significant learning can take place between GTAs when they have the opportunity to discuss and reflect on their actual practice contexts and experiences together. Additionally, for both new and experienced GTAs, the observations have enhanced their repertoire of teaching methods and approaches to try out in their own classes. They have also specifically supported the new GTAs to take a selfreflective stance to their teaching from the very beginning. In the two years since the observations took place, the GTAs confirm that they have continued this practice of selfreflecting on their teaching.

In this unique project, the GTAs themselves have been involved in evaluating their own experiences, allowing deeper and richer insights to be gained about the impact on their development and teaching practices. Apparent from the findings and the summaries is the benefit of interdisciplinary observations. These experiences provide exposure to other teaching environments and contexts that they may not otherwise gain. The findings confirm that this was an initial attraction for participating in the project for some of the GTAs. This exposure fosters expanded thinking about individual teaching practices and, significantly, encourages disciplinary 
methods to be viewed from another perspective. Specifically, it appears to give the GTAs an outsider view to some extent, with which, by comparing to other disciplines and teaching environments, they consider their own contexts with a fresh pair of eyes. In doing so, they begin to question some of the methods used in their disciplines and become aware of how teaching approaches and formats can become ingrained. The value of developing this critical perspective at this point in their teaching careers cannot be overstated. It means that, as they progress, they will be adopting a more scholarly approach to teaching by questioning whether the methods that they are using are the most effective or simply entrenched practices. They will also be continually open to the advantages of learning from other disciplines.

Finally, the findings demonstrate the positive effect of the post-observation learning conversations. These provide opportunities for discussion and reflection that may not otherwise be available to GTAs. At a point when they feel inexperienced and potentially very unsure of themselves as teachers, they can talk to others who are feeling similarly challenged and share ideas, concerns and experiences in a low stakes and non-intimidating way.

A limitation of the study is that it is a pilot and therefore reports the experiences of a small group of GTAs. Additionally, by their responding to the invitation to participate, it is clear that they were already motivated to explore and enhance their teaching practices. Whilst the evaluation approach utilised was essential to the collaborative nature of this project, a positive subjective bias may also underpin the analysis to some extent. Further research would be beneficial to explore the experiences of this type of observation process with a wider community of GTA participants. Such research could take a longitudinal perspective to identify whether significant changes and enhancements to practice continue to ensue following the observation process. It might also be of value to explore and consider the impact of the different elements of the process. A challenge with the peer (equal-status) observation approach is how and where those with more teaching knowledge and experience may be involved. The academic developer did not participate in or review the post-observation learning conversations, which might have been useful to augment the discussions taking place and address the promotion of any questionable practices. It would be useful to consider further the positioning of all stakeholders in the process, especially when rolling out to larger groups, so that peer learning is effectively supported and enriched.

\section{Conclusion}

The project reported on here has been a collaborative endeavour between an academic developer and eight dedicated and enthusiastic GTAs. As a pilot, GTA involvement has been important at every step of the process, from the design stage to the evaluation. With their scholarly input, we have learnt a great deal about the positive impact and outcomes of this particular peer observation approach. This paper provides a rich picture of this GTA group's professional development experiences through their explicit engagement in the SoTL-aligned peer observation framework (Engin, 2016). We encourage further collaborative endeavours so that GTAs are viewed not just as recipients of training, provision, etc., but as active agents in 
framing their professional needs and shaping the range of developmental opportunities available.

\section{Reference List}

Beaton, F. (2017) 'Just in time and future-proofing? Policy, challenges and opportunities in the professional development of part-time teachers.' International Journal for Academic Development, 22(1), 19-30. Available at: https://doi.org/10.1080/1360144X.2016.1261354 (Accessed: 17 August 2018).

Chadha, D. (2013) 'Reconceptualising and reframing graduate teaching assistant (GTA) provision for a research-intensive institution.' Teaching in Higher Education, 18(2), 205-217. Available at: https://doi.org/10.1080/13562517.2012.696537 (Accessed: 15 December 2015).

Chamberlain, J.M., D'Artrey, M. and Rowe, D.A. (2011) 'Peer observation of teaching: a decoupled process.' Active Learning in Higher Education, 12(3), 189-201. Available at: https://doi.org/10.1177/1469787411415083 (Accessed: 15 July 2019).

Deshler, J.M. (2015) 'Using modified lesson study with mathematics post-graduate teaching assistants.' Research in Mathematics Education, 17(3), 242-243. Available at: https://doi.org/10.1080/14794802.2015.1105757 (Accessed: 17 July 2019).

Drew, S., Phelan, L., Lindsay, K., Carbone, A., Ross, B., Wood, K., Stoney, S. and Cottman, C. (2017) 'Formative observation of teaching: focusing peer assistance on teachers' developmental goals.' Assessment and Evaluation in Higher Education, 42(6), 914-929. Available at: https://doi.org/10.1080/02602938.2016.1209733 (Accessed: 15 July 2019).

Engin, M. (2016) Enhancing the status of peer observation through the scholarship of teaching and learning. International Journal for Academic Development, 21(4), 377-382. Available at: https://doi.org/10.1080/1360144X.2016.1225576 (Accessed: 15 July 2019).

Gosling, D. (2002) Models of peer observation of teaching. Available at: https://www.researchgate.net/profile/David-Gosling4/publication/267687499 Models of Peer Observation of Teaching/links/545b64810cf249070 a7955d3/Models-of-Peer-Observation-of-Teaching.pdf (Accessed: 16 January 2019).

Hammersley-Fletcher, L. and Orsmond, P. (2005) 'Reflecting on reflective practices within peer observation.' Studies in Higher Education, 30(2), 213-224. Available at: https://doi.org/10.1080/03075070500043358 (Accessed: 16 July 2019). 
Hendry, G.D., Bell, A. and Thomson, K. (2014) 'Learning by observing a peer's teaching situation.' International Journal for Academic Development, 19(4), 318-329. Available at: https://doi.org/10.1080/1360144X.2013.848806 (Accessed: 16 July 2019).

Howlett, K.M. and Nguyen, H.L. (2020) 'Autoethnographic reflections of an international graduate teaching assistant's co-teaching experiences.' Journal of International Students, 10(2), 401-419. Available at: https://doi.org/10.32674/jis.v10i2.774 (Accessed: 11 April 2021).

Joyce, A. and Hassenfeldt, T.A. (2020) 'Utility of a peer teaching mentor to graduate teaching assistants.' College Teaching, 68(1), 12-19. Available at: https://doi.org/10.1080/87567555.2019.1689906 (Accessed: 11 April 2021).

Lampley, S.A., Gardner, G.E. and Barlow, A.T. (2018) 'Exploring pedagogical content knowledge of biology graduate teaching assistants through their participation in lesson study.' Teaching in Higher Education, 23(4), 468-487. Available at: https://doi.org/10.1080/13562517.2017.1414786 (Accessed: 11 April 2021).

Lockwood, S.A., Miller, A.J. and Cromie, M.M. (2014) 'Preparing future Biology faculty: an advanced professional development program for graduate students.' The American Biology Teacher, 76(1), 17-21. Available at: https://doi.org/10.1525/abt.2014.76.1.5 (Accessed: 11 April 2021).

Lueddeke, G.R. (1997) 'Training postgraduates for teaching: considerations for programme planning and development.' Teaching in Higher Education, 2(2), 141-151. Available at: https://doi.org/10.1080/1356251970020204 (Accessed: 30 December 2015).

McMahon, T., Barrett, T. and O'Neill, G. (2007) 'Using observation of teaching to improve quality: finding your way through the muddle of competing conceptions, confusion of practice and mutually exclusive intentions.' Teaching in Higher Education, 12(4), 499-511. Available at: https://doi.org/10.1080/13562510701415607 (Accessed: 16 July 2019).

Raaper, R. (2018) 'Peacekeepers and machine factories: tracing graduate teaching assistant subjectivity in a neoliberalised university.' British Journal of Sociology of Education, 39(4), 421435. Available at: https://doi.org/10.1080/01425692.2017.1367269 (Accessed: 16 January 2019).

Race, P. (2009) Using peer observation to enhance teaching. Leeds, UK: Leeds Met Press. ISBN 978-0-9560099-7-5.

Reinholz, D.L. (2017) 'Not-so-critical friends: graduate student instructors and peer feedback.' International Journal for the Scholarship of Teaching and Learning, 11(2), Article 10. Available at: https://doi.org/10.20429/ijsotl.2017.110210 (Accessed: 2 July 2019). 
Reinholz, D.L., Cox, M. and Croke, R. (2015) 'Supporting graduate student instructors in calculus.' International Journal for the Scholarship of Teaching and Learning, 9(2), Article 11. Available at: https://doi.org/10.20429/ijsotl.2015.090211 (Accessed: 2 July 2019).

Sozer, E.M., Zeybekoglu, Z. and Alayli, A. (2019) 'Examining graduate teaching assistants' conceptions of and readiness for effective teaching in a non-profit Turkish university.' Innovations in Education and Teaching International, 56(3), 373-384. Available at: https://doi.org/10.1080/14703297.2018.1453369 (Accessed: 11 April 2021).

Stocks, C. (2018) 'Supporting graduate teaching assistants' (GTA) continual professional learning: the benefits of using action learning.' Journal of Perspectives in Applied Academic Practice, 6(1), 84-90. Available at: https://doi.org/10.14297/jpaap.v6i1.288 (Accessed: 17 July 2019).

Tenenberg, J. (2016) 'Learning through observing peers in practice.' Studies in Higher Education, 41(4), 756-773. Available at: https://doi.org/10.1080/03075079.2014.950954 (Accessed: 5 August 2019).

Torres, A.C., Lopes, A., Valente, J.M.S. and Mouraz, A. (2017) 'What catches the eye in class observation? Observers' perspectives in a multidisciplinary peer observation of teaching program.' Teaching in Higher Education, 22(7), 822-838. Available at:

https://doi.org/10.1080/13562517.2017.1301907 (Accessed: 11 January 2019). 


\section{Appendix 1: Observation documentation template}

\section{Pre-observation discussion}

The observer and observee should meet before the observed teaching session so that both understand the context of the session and have agreed the areas of focus for that observation. The form below will help you to structure your pre-observation discussion.

\begin{tabular}{|c|c|}
\hline Observee name: & Observer name: \\
\hline Date, time and place: & $\begin{array}{l}\text { Approximate number of students and level } \\
\text { of study (e.g., first year, second year): }\end{array}$ \\
\hline $\begin{array}{l}\text { Kind of teaching/learning context (e.g., lecture, } \\
\text { tutorial, seminar, demonstration, practical, } \\
\text { etc): }\end{array}$ & Session topic: \\
\hline \multicolumn{2}{|c|}{ Aims/learning objectives for the session (what should the students get out of the session?): } \\
\hline \multicolumn{2}{|c|}{ Teaching role/responsibilities of the observee in the session: } \\
\hline \multicolumn{2}{|c|}{ What areas the observee would like to get some feedback on: } \\
\hline \multicolumn{2}{|c|}{$\begin{array}{l}\text { Anything else that would be useful to discuss? You may find it helpful to discuss areas that } \\
\text { the observee would not like to get feedback on, e.g., issues that they are already aware of or } \\
\text { areas that are outside of their control. }\end{array}$} \\
\hline \multicolumn{2}{|c|}{$\begin{array}{l}\text { Have you both agreed: } \\
\text { Where the observer will sit? Whether they will be introduced to the class? How long the } \\
\text { observation will last? When you will have the post-observation discussion? }\end{array}$} \\
\hline \multicolumn{2}{|c|}{$\begin{array}{l}\text { The observer should use this space to consider what they might also like to focus on in the } \\
\text { observation with regards to their own teaching development. For example, would like to see } \\
\text { how others may deal with difficult questions, get students interacting with each other, etc, etc? }\end{array}$} \\
\hline
\end{tabular}


The observation session

The observer may find it useful to use the form below to make notes during the observation.

\section{Observation notes}

Observations on the areas that the observee would like to get feedback on (you may find it useful to list these areas below):

Student engagement observations:

Teaching approach/activities observations:

Observations about the areas that I would like to particularly focus on (you may find it useful to list these areas below): 


\section{Post-observation discussion - a 'learning conversation'}

The observer and observee will meet after the observed teaching session for a 'learning conversation'. The observer will discuss their observation notes, particularly those focused on the areas that were identified by the observee in the pre-observation meeting. Both parties will then reflect individually and/or together on what they have learnt from this observation experience and how it may inform their further teaching practice. The form below should be completed by both the observee and the observer.

Notes (use this space for any notes that you want to make during the post-observation discussion):

\section{Reflection}

In relation to my teaching practice, what are the most significant things that have come out of this observation experience for me?

How will I try to act on what I have learnt from this particular experience? 